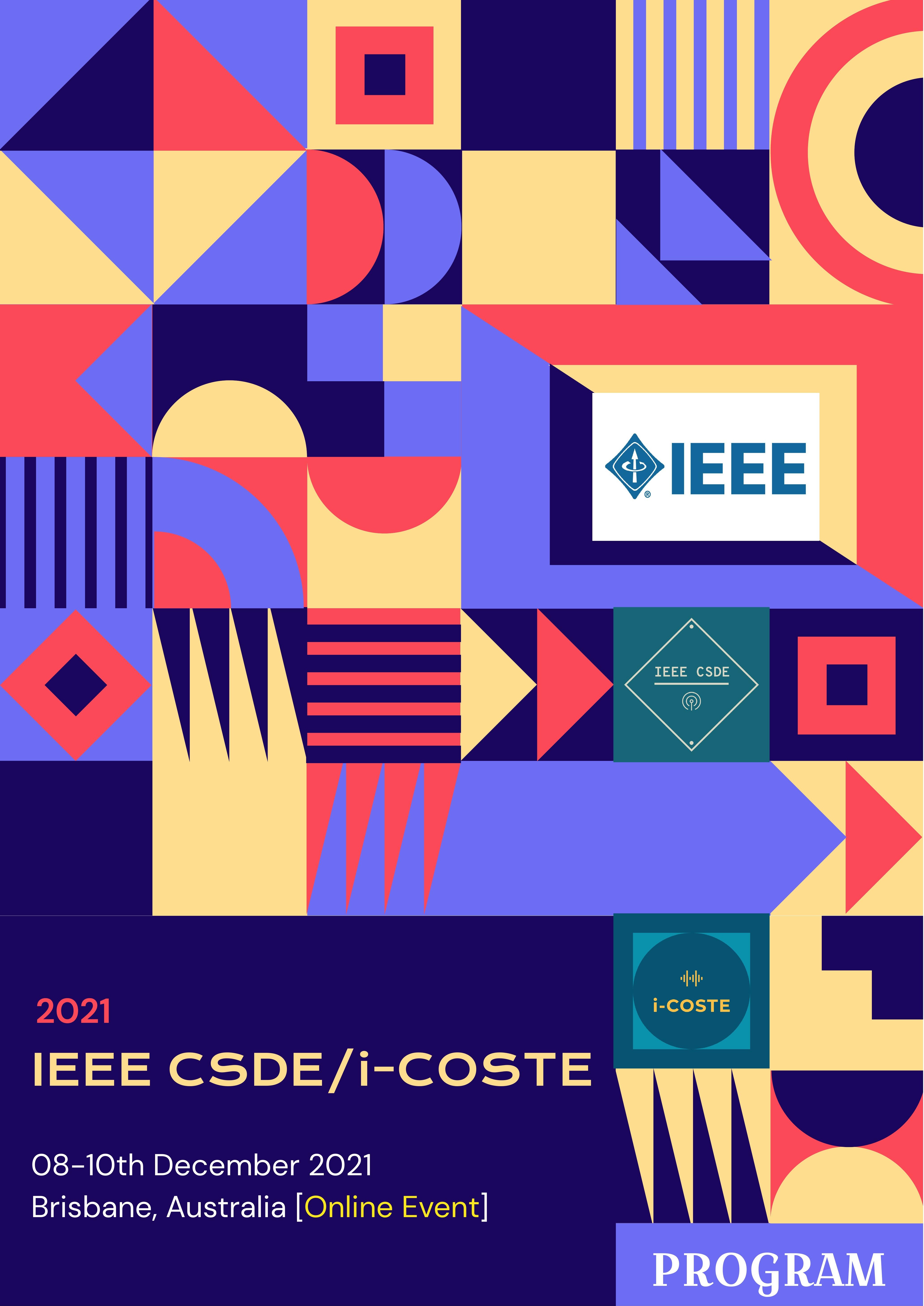




\section{GENERAL CHAIR MESSAGE}

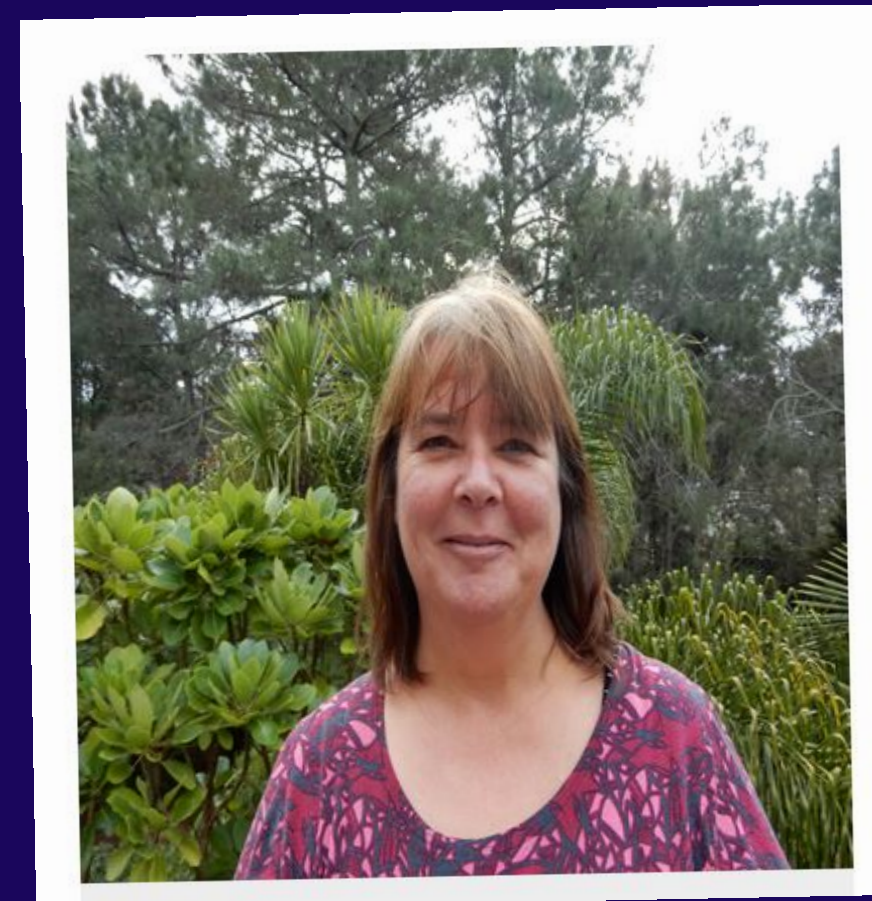

Dear IEEE CSDE/-i-COSTE 2021 Authors, Invited Guests, and Delegates

As the General Chair of the IEEE Asia-Pacific Conference on Computer Science and Data Engineering (CSDE 2021)/ International Conference on Sustainable Technology and Engineering 2021 (i-COSTE 2021), it gives us immense pleasure to welcome over 150 guests and delegates from Universities, Research Organizations, Industry, Government, and NGOs from over 15 countries around the world to the Conference. Also, a very warm welcome to the beautiful and Australian Tropical Capital Brisbane in a virtual way. COVID-19 changed many of our current practices in 2021 including face-to-face conferences but we are thankful to all conference authors and delegates who supported our idea of arranging this conference online.

CSDE \& i-COSTE 2021 received just below 386 submissions from 21 countries with 810 co-authors across six continents. Authors from China, Australia, Japan, the United States, Germany, India, Bangladesh, Fiji, the United Kingdom, Korea, Malaysia, South Africa, and Brazil had respectively submitted the highest number of papers to the Conference. Each submission was peer-reviewed by at least two experts in the respective fields and the acceptance decisions were based on at least two consistent recommendations, ensuring high quality and standard of the Conference and its proceedings. In total, 150 papers from 810 authors were finally accepted and are included in the Conference Proceedings and Program. From these authors, 120 have one accepted paper, 25 have two accepted papers and 5 have 3 or more accepted papers. The accepted and scheduled papers will be presented in 23 oral sessions over a 3-day period. A few accepted papers were submitted to the special sessions of the Conference.

We are also privileged to have 5 distinguished keynote speakers, one PhD thesis symposim. We would like to take this opportunity and thank all distinguished keynote speakers, subject track chairs, session chairs, numerous reviewers and authors, and all members of the technical and organization committees. We sincerely thank the Conference's financial sponsor IEEE and technical co-sponsors, and all supporting universities from several countries. Without their great support, this conference could not have been successful. We wish all of you a very pleasant and fruitful online time at the Conference, and we hope that you could have an opportunity to Brishbane in a future conference, hosted by us, when the COVID-19 pandemic is settled down.

Now officially I announce the opening of IEEE CSDE/i-COSTE 2021. Over to MC. 


\section{GENERAL CHAIR BIO}

Suzanne Wilkinson is a Professor of Construction Management in the New School for Built Environment, Massey University, Director of Postgraduate Studies, School for Built Environment and Associate Dean (Research), College of Sciences, Massey University. She has a PhD in Construction Management, and a BEng (Hons) in Civil Engineering, both from Oxford Brookes University, and a Graduate Diploma in Business Studies (Dispute Resolution) from Massey University. Prior to working at Massey University, Suzanne was at the University of Auckland, Department of Civil and Environmental Engineering, from lecturer to Professor and Deputy Head of Department.

Suzanne's research focuses on resilience, disaster management, construction innovation and smart cities. She is interested in how cities, communities and organisations plan for disasters and manage hazard events and has a particular interest in how cities, communities and organisations rebuild and recover. Suzanne has been advisor to organisations on resilience building and disaster recovery, most recently including Auckland Council, Government Agencies in New Zealand and Hunter Water in Australia. Suzanne has been Principal Investigator and Research Leader on many projects, including a recent 5 year, \$10 million NZD project, where she is programme lead, on building capacity and capability for the construction sector and a recently completed 4million NZD Principal Investigator for the Urban theme in the National Science Challenge: Resilience to Nature's Challenges. She has published over 300 research papers and co-written 3 books, the most recent being Resilient Post Disaster Recovery Through Building Back Better (Routledge in 2019), with her colleagues Sandeeka Mannakkara and Regan Potangaroa. Suzanne is a keen PhD supervisor and has now supervised to completion over 30 PhD students. 


\section{ADVISORY COMMITTEE}

Professor Yang Xiang, Swinburne University of Technology, Australia

Professor Katsunori Shimohara, Doshisha University, Japan

Professor Alamgir Hossain, Anglia Ruskin University, UK

Professor Takashi Washio, Osaka University, Japan

Professor Gautam Das, University of Texas, USA

General Chair

Assoc. Professor M G M Khan, The University of The South Pacific, Fiji

General Co-Chair

Professor Girija Chetty, University of Canberra, Australia

Assoc. Professor Feng Xia, Federation University, Australia

\section{Steering Committee Chair and Co-Chair}

Professor Takeshi Koshiba, Waseda University, Japan

Assoc. Professor Musfique Anwar, Jahangirnagar University, Bangladesh

Technical Program Chair and Co-Chair

Assoc. Professor Bibhya Sharma, The University of The South Pacific, Fiji

Dr. Salahuddin Azad, CQUniversity, Australia

Dr. Md. Ashraful Alam, BRAC University, Bangladesh

Publication and Financial Chair and Co-Chair

Professor A B M Shawkat Ali, CQUniversity, Australia

Dr. Kaylash Chaudhary, The University of The South Pacific, Fiji

Tutorial Chair and Co-Chair

Assoc. Professor Md Golam Rabiul Alam, BRAC University, Bangladesh

Dr. Ritesh Ajoodha, The University of the Witwatersrand, South Africa

Scholarship and Award Chair

Dr. Michael John Dinneen, The University of Auckland, New Zealand

Dr. Mamunur Rashid, CQUniversity, Australia

Publicity Chair and Co-Chair

Dr. Morshed Chowdhury, Deakin University, Australia

Dr. Yi Zuo, Dalian Maritime University, China

Exhibition and Sponsorship Chair and Co-Chair

Dr. Hayati Yassin, Universiti Brunei Darussalam, Brunei

Dr. Biplob Roy, CQUniversity, Australia Industry Track Chair

Nhlanganiso Khoza, Savage \& Suave, South Africa

Local Arrangement Chair and Co-Chair

Dr. Meena Jha, CQUniversity, Australia

Zahra Mungloo-Dilmohamud, University of Mauritius, Mauritius

Students Activities Chair and Co-Chair

Feisal Hadi O Masmali, Jazan University, Saudi Arabia

Tresia Holtzhausen, Nelson Mandela University, South Africa
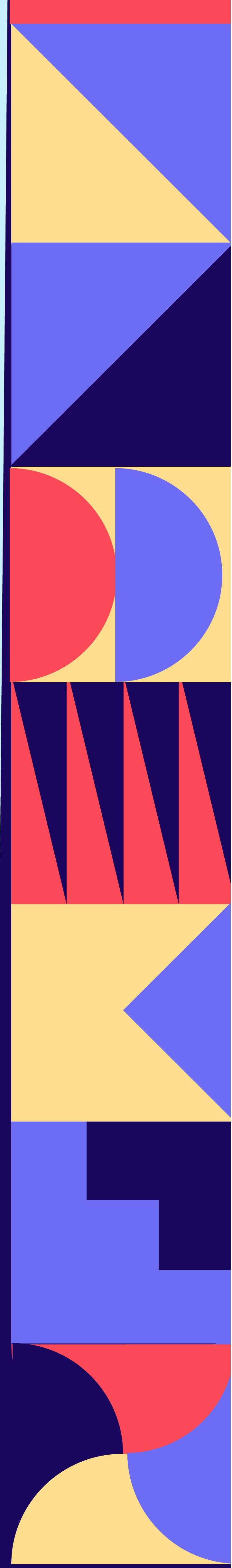

Web Coordinator

Jashnil Kumar, iLab Fiji, Fiji 
ADVISORY COMMITTEE

Professor Akhtar Kalam, Victoria University, Australia

Professor Young-Ho LEE, Korea Maritime \& Ocean University, South Korea

Professor Aiguo Patrick Hu, The University of Auckland, New Zealand

Professor Syed Anisul Haque, University of Waterloo, Canada

Professor Shizhang Qiao, The University of Adelaide, Australia

\section{General Chair}

Professor Suzanne Wilkinson, Massey University, New Zealand General Co-Chair

Professor Rajkumar S. Pant, Indian Institute of Technology Bombay, India

Professor A B M Shawkat Ali, CQUniversity, Australia

Technical Program Chair and Co-chair

Dr. GM Shafiullah, Murdoch University, Australia

Dr. S.D.G.S.P. Gunawardane, University of Peradeniya, Sri Lanka Special Session Chair

A/Professor Kamal Jaafar, The University of Wollongong, UAE

Women in Engineering Chair and Co-Chair

Dr Anuradha Mathrani, Massey University, New Zealand

Dr Wan Yun Hong, Universiti Brunei Darussalam, Brunei Darussalam Publication Chair

Dr. Min-Sung Kim, Korean Maritime and Ocean University, Republic of Korea Tutorial Chair

Dr Sanjay Mathrani, Massey University, New Zealand Scholarship and Award Chair

Dr. Mohammad Taufiqul Arif - Deakin University, Australia

\section{Publicity Chair}

Assoc. Professor Jahangir Hossain, University of Technology Sydney, Australia

Exhibition and Sponsorship Chair and Co-Chair

Assoc. Professor Nasser Hosseinzadeh, Deakin University, Australia

Dr. Raid Al-Aomar, German Jordanian University, Jordan

Industry and Local Arrangement Chair and Co-Chair

Dr. Nur Hassan, CQUniversity, Australia

Dr. Mejbaul Haque, Australian National University, Australia

Students Activities Chair and Co-Chair

A/Professor Abu Shadat Muhammad Sayem, Chittagong University of Engineering \&

Technology, Bangladesh

Dr Shelvin Chand, CSIRO, Australia

Web Coordinator

Jashnil Kumar, iLab Fiji, Fiji
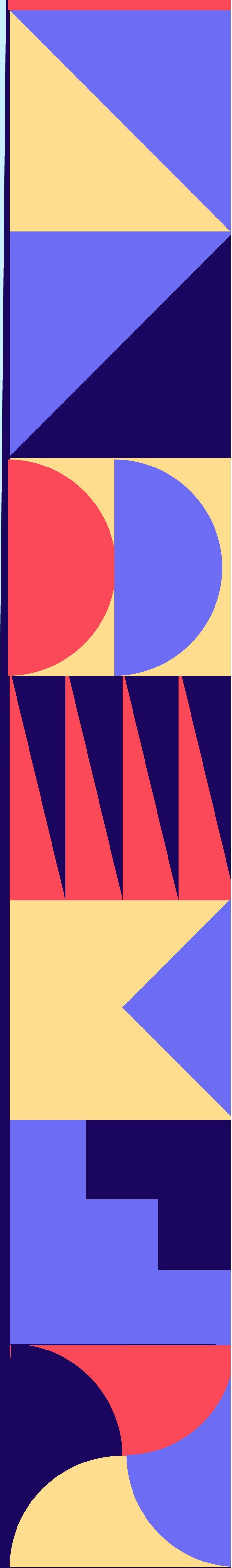
Professor A H M Kamal, Jatiya Kabi Kazi Nazrul Islam University, Bangladesh

Dr Ahsan Morshed, CQUniversity, Bangladesh

Professor Ahsan-UI-Ambia, Islamic University, Bangladesh

Mr Alvin Prasad, The University of Fiji, Fiji

Mr Anal Kumar, Fiji National University, Fiji

Dr Andrew Chiou, CQUniversity, Australia

Dr Anuradha Mathrani, Massey University, New Zealand

Assoc. Prof. Ashraful Alam, BRAC University, Bangladesh

Dr Arif Khan, Fiji National University, Fiji

Mr Atishnal Chand, The University of the South Pacific, Fiji

Mr Badan Das, Jahangirnagar University, Bangladesh

Assoc. Prof. Bibhya Sharma, The University of the South Pacific, Fiji

Professor Bikash C. Singh, Islamic University,Bangladesh

Mr. Bimal Kumar, Fiji National University, Fiji

Mr. Biplob Roy, CQUniversity, Australia

Assoc. Prof. Feng Xia, Federation University, Australia

Professor Girija Chetty, Canberra University, Australia

Dr GM Shafiullah, Murdoch University, Australia

Assoc. Prof. Habibur Rahman, Islamic University, Bangladesh

Dr Hayati Yassin, University Brunei Darussalam, Brunei Darussalam

Dr Irwanto Irwanto, Jakarta State University, Indonesia

Dr Jai Raj, The University of the South Pacific, Fiji

Assoc. Prof. Jahangir Hossain, University Technology Sydney, Australia

Dr Kabir Mamun, The University of the South Pacific, Fiji

Mr Kunal Kumar, The University of Fiji, Fiji

Mr Lionel Joseph, The University of Fiji, Fiji

Assoc. Prof. M G M Khan, The University of the South Pacific, Fiji

Dr Mamunur Rashid, CQUniversity, Australia

Professor Md Aktaruzzaman, Islamic University, Bangladesh

Assoc. Prof. Md Golam Rabiul Alam, BRAC University, Bangladesh

Professor Md. Ibrahim Abdullah, Islamic University, Bangladesh

Dr Krishna Raghuwaiya, The University of the South Pacific, Fiji

Professor Md Khademul Islam Molla, Rajshaihi University, Bangladesh

Professor Md. Rafiqul Islam, Khulna University, Bangladesh

Professor Md. Shariful Islam, Islamic University, Bangladesh

Dr S.D.G.S.P. Gunawardane, University of Peradeniya, Sri Lanka

Professor Md. Zahidul Islam, Islamic University, Bangladesh

Assoc. Prof. Kamal Jaafar, University of Wollongong, UAE

Dr Meena Jha, CQUniversity, Australia

Dr Michael John Dinneen, Auckland University, New Zealand

Professor Mijanur Rahman, Jatiya Kabi Kazi Nazrul Islam University, Bangladesh

Dr Mejbaul Haque, Australian National University, Australia

Dr. Mohammed Moni, University of Queensland, Australia

Professor Musfique Answer, Jahangirnagar University, Bangladesh

Dr Nahina Islam, CQUniversity, Australia

Mr Neeraj Sharma, The University of Fiji, Fiji

Mr Nhlanganiso Khoza, Savage \& Suave, South Africa

Dr Nur Hassan, CQUniversity, Australia

Professor Paresh Chandra Barman, Islamic University, Bangladesh

Ms Pritika Reddy, The University of the South Pacific, Fiji

Assoc. Prof. Rajesh Palit, North South University, Bangladesh

Professor Rajkumar S. Pant, IIIT Bombay, India

Dr Rakib Ahmed, Australian Taxation Office, Australia

Dr Ramendra Prasad, The University of Fiji, Fiji

Dr Rahul Kumar, The University of the South Pacific, Fiji

Professor Robiul Hoque, Islamic University, Bangladesh

Dr Salahuddin Azad, CQUniversity, Australia

Dr Sanjay Jha, KOI, Australia

Dr Sanjay Mathrani, Massey University, New Zealand

Professor Shamim Ahmad, Rajshahi University, Bangladesh

Dr Shelvin Chand, CSIRO, Australia

Ms Swaran Ravindra, The University of the South Pacific, Fiji

Dr Taufiqul Arif, Deakin University, Australia

Professor Tapan Kumar Jodder, Islamic University, Bangladesh

Ms. Tresia Holtzhausen, Nelson Mandela University, South Africa

Professor Tushar Shaha, Jatiya Kabi Kazi Nazrul Islam University, Bangladesh

Ms. Zahra Mungloo-Dilmohamud, University of Mauritius, Mauritius 


\section{KEYNOTE SPEAKERS}

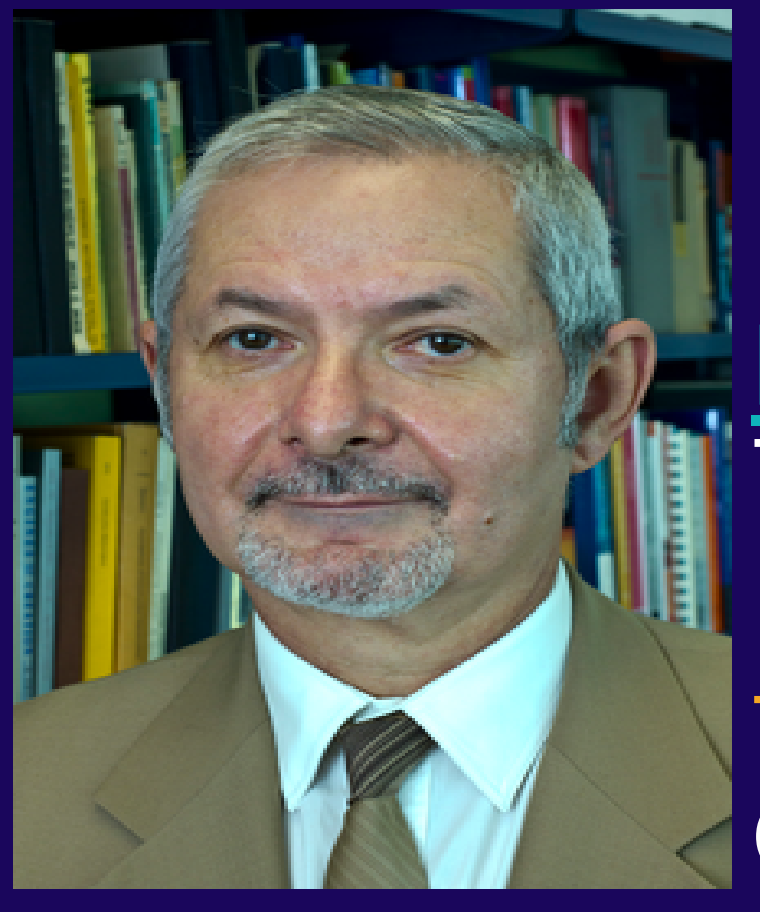

Professor Mohamed Medhat Gaber Birmingham City University United Kingdom

Topic: Deep Convolutional Neural Networks for Covid-19 Detection from Chest X-ray Images: From Class Decomposition to Selfsupervision
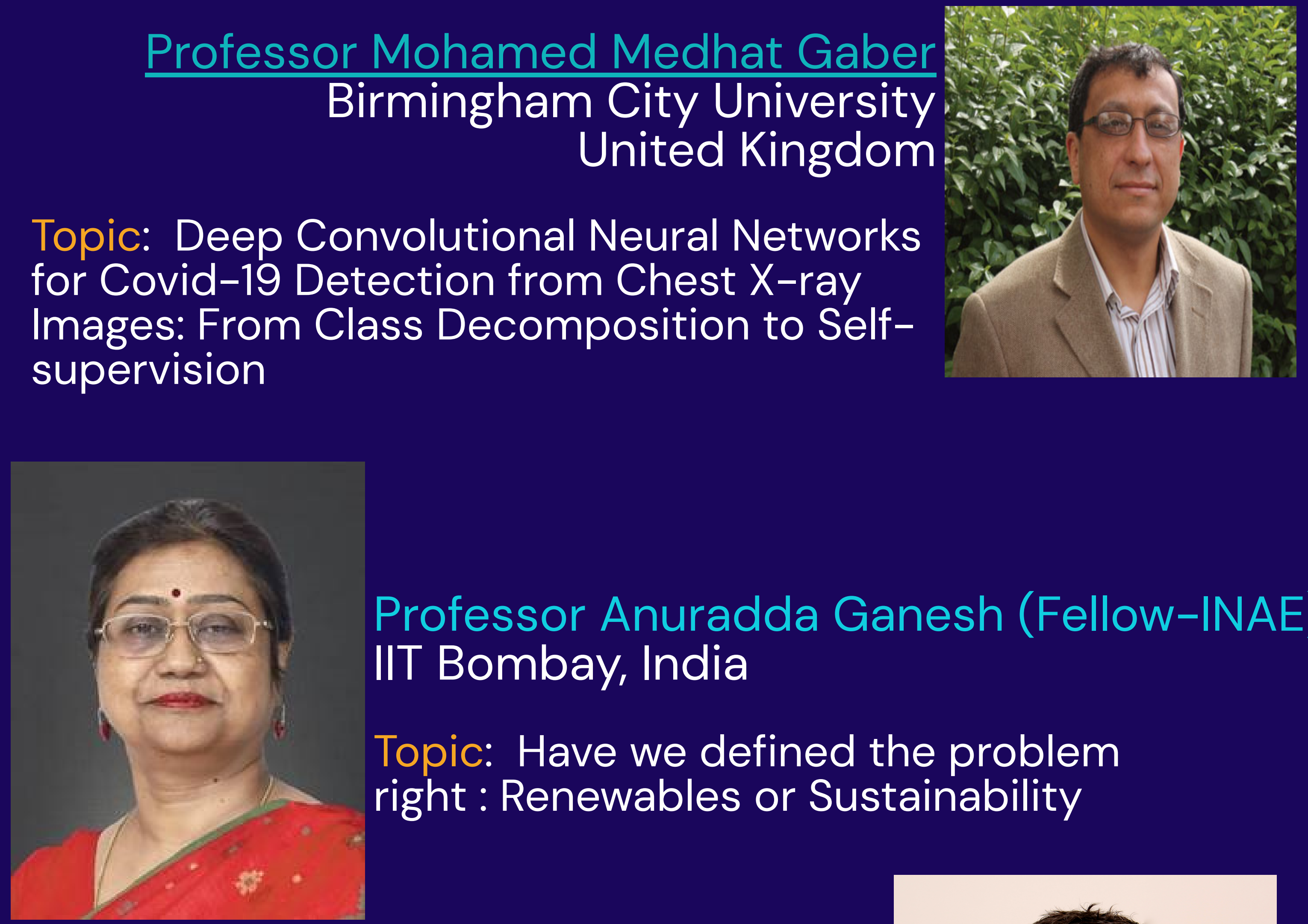

Professor Anuradda Ganesh (Fellow-INAE) IIT Bombay, India

Topic: Have we defined the problem right : Renewables or Sustainability

Professor Richard Sinnott The University of Melbourne, Australia Topic: Big Data Platforms for Applied Research: from Theory to the Real World
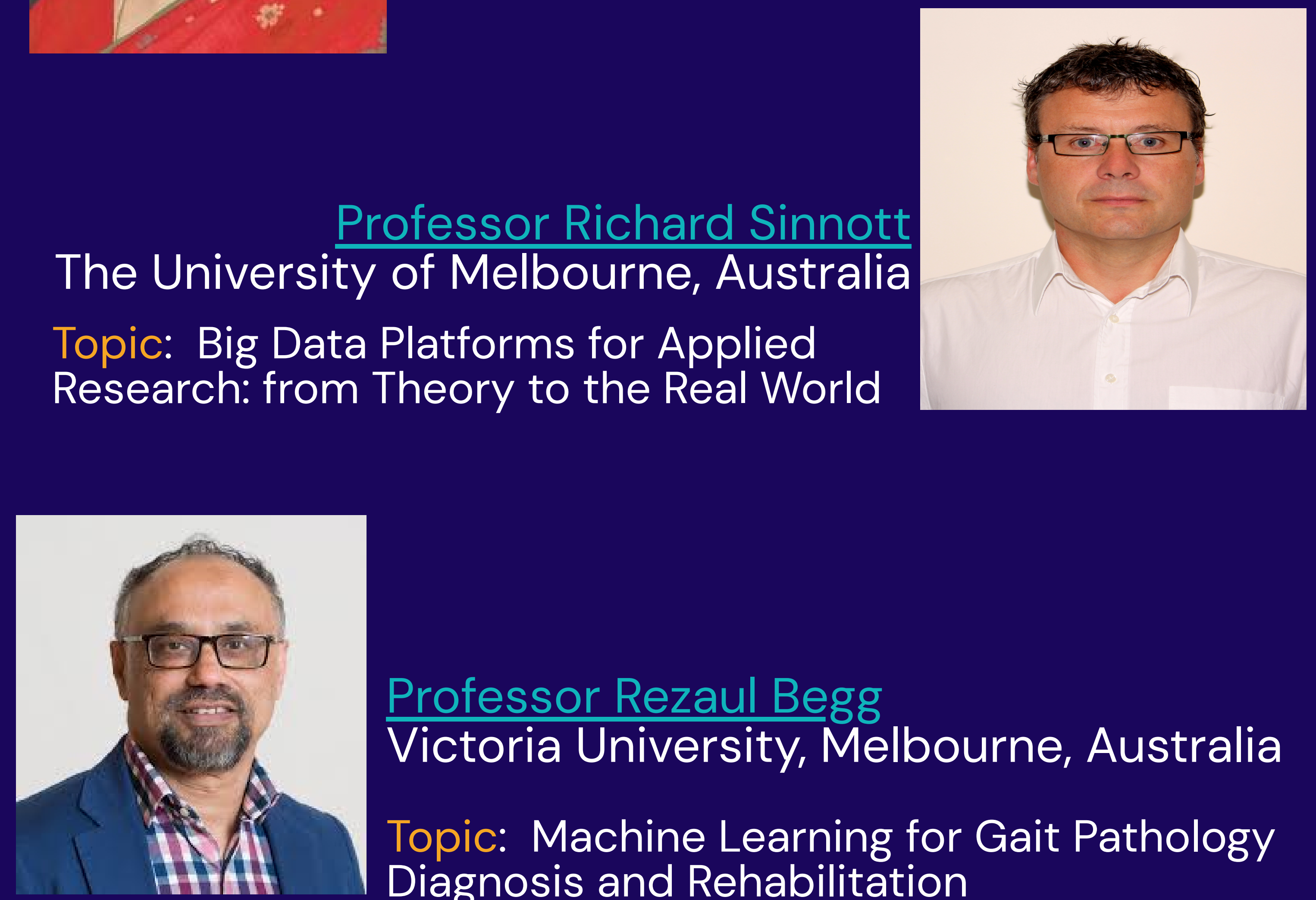

Professor Rezaul Begg

Victoria University, Melbourne, Australia

Topic: Machine Learning for Gait Pathology Diagnosis and Rehabilitation 


\section{CONFERENCE PROGRAM}

DAY - 1: 08th December 2021
16.00-16.30 || Virtual Registration and Cocktail Reception
AEST Virtual Lounge \& Bar Area - Zoom 1
OPENING CEREMONY

16.30-17.15 || Keynote Talk ONE - Zoom 1

17.15-18.00 || Keynote Talk TWO - Zoom 1

18.00-19.30 || PhD Thesis Symposium - Zoom 1

18.00-20.00 || Session 1 - Zoom 2

DAY - 2: 09th December 2021

09.00-10.30 \| Session 2 - Zoom 1; $\quad$ Session 3: Zoom 2; $\quad$ Session 4: Zoom 3 AEST

10.30-11.00 || Break Time for Tea and Coffee

11.00-13.00 || Session 5 - Zoom 1; Session 6: Zoom 2; $\quad$ Session 7: Zoom 3

13.00-14.00 || Lunch Break

14.00-16.00 || Session 8-Zoom 1; Session 9: Zoom 2; Session 10: Zoom 3

16.00-16.45 || Keynote Talk Three - Zoom 1

16.50-17.35 $\quad \| \quad$ Keynote Talk Four - Zoom 1

DAY - 3: 10th December 2021

09.00-10.30 || Session 11 - Zoom 1; Session 12: Zoom 2; Session 13: Zoom 3 AEST

10.30-11.00 || Break Time for Tea and Coffee

11.00-13.00 || Session 14 - Zoom 1; Session 15: Zoom 2; Session 16: Zoom 3

13.00-14.00 || Lunch Break

14.00-16.00 || Session 17 - Zoom 1; Session 18: Zoom 2; Session 19: Zoom 3

16.00-16.45 || Keynote Talk Five - Zoom 1

16.50-17.50 || Closing and Award Ceremony 


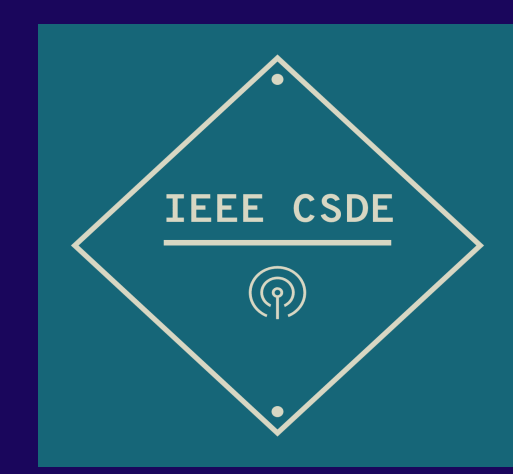

Zoom 1 Link

Zoom 2 Link

Zoom 3 Link
Meeting ID: 91229124156

Meeting ID: 99870482510

Meeting ID: 96481020864
Passcode: 529147

Passcode: 998668

Passcode: 739330

\section{IEEE CSDE \& i-COSTE 2021 - Day 1}

Date: 08th December 2021; Time: 16:00 - 16:30 AEST (Australian Eastern Standard Time)

OPENING CEREMONY

CHIEF GUEST

Professor Suzanne Wilkinson, Massey University, New Zealand Associate Professor M G M Khan, The University of The South Pacific, Fiji

\section{CONFERENCE REPORT}

Professor A B M Shawkat Ali, The University of Fiji, Fiji

\section{MASTER OF CEREMONIES}

Shayneel Chand, The University of Fiji, Fiji

\section{KEYNOTE TALK}

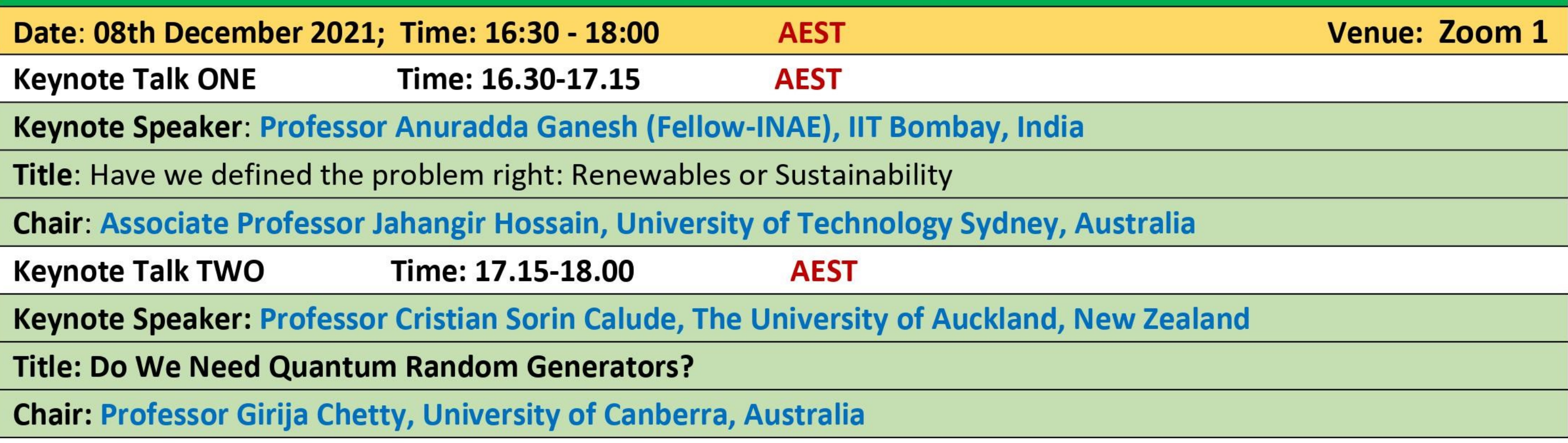

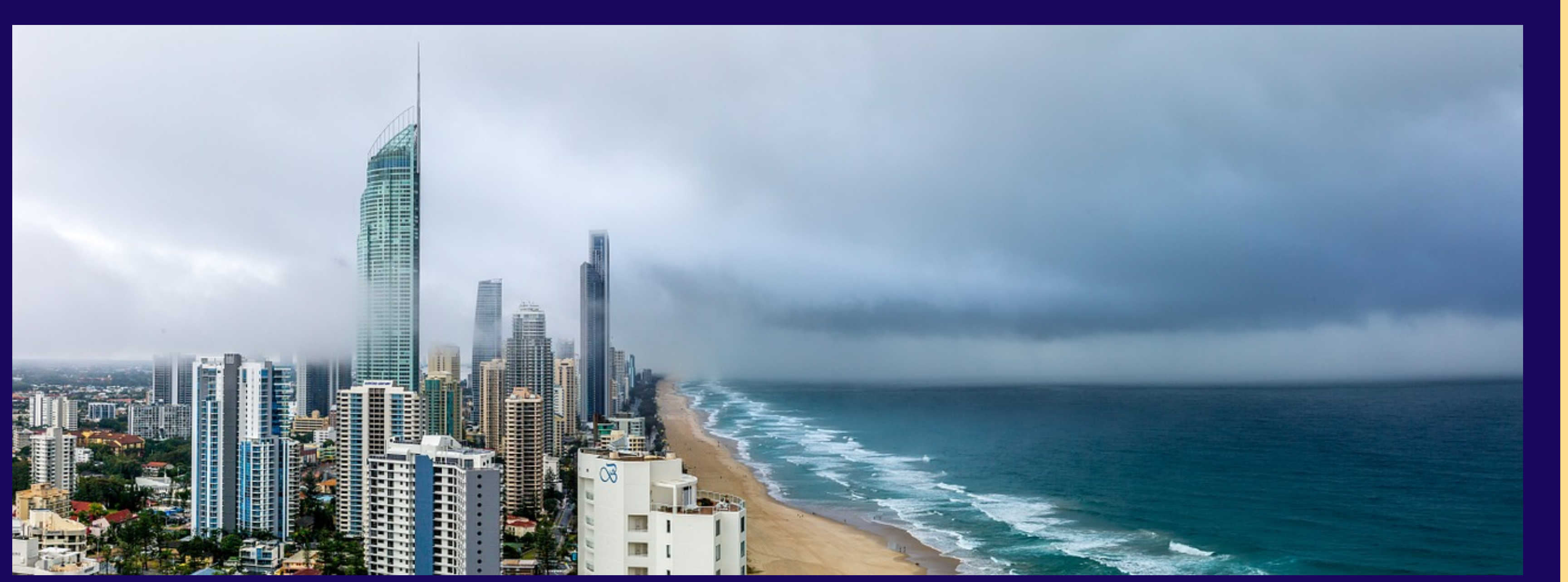




\section{Keynote Talk ONE}

Speaker: Professor Anuradda Ganesh (Fellow-INAE), IIT Bombay, India

Topic: Have we defined the problem right: Renewables or Sustainability

\section{BRIEF BIO}

Professor Dr Anuradda Ganesh is the Chief Technical Advisor at the Cummins Technologies India Pvt Ltd. She advises on innovative technology, regulatory trends and policy. She also advises on University and Government collaboration areas and strategic partnerships. In her earlier roles, she established and led the Research and Innovation for Cummins Tech Center (India), to address the fit-for-market requirements for Cummins India products. She was the Director of Cummins Research and Technology India, focusing on the application of Analysis Led Design tools to reduce the time and cost of product development.

As a $\mathrm{PhD}$ in Chemical Engineering, she brings in a unique combination of excellence in academia as well as industry. Prior to joining the industry, she had an extensive career in Academia and Research as a Professor of the Department of Energy Science and Engineering (DESE) at the Indian Institute of Technology Bombay (IITB). She has contributed extensively to the field of renewable energy. Her research spans different subjects including alternate fuels (producer and syngas), chemicals (using supercritical fluid extraction) from biomass and "smart-carbon", underground coal gasification, and energy systems modelling. She has contributed to the subject with over 60 international publications, over 4000 citations, supervised $16 \mathrm{PhDs}$ and has half a dozen granted patents.

In 2020, she was inducted as a Fellow of the Indian Nation Academy of Engineering. She is the recipient of the SWE Prism Award in 2021 for her impact on Society as well as the engineering community. She has shared her journey and tips in an e-book published in 2021, by the Confederation of Indian Industries (CII) on 51 Indian women achievers in STEM. 


\section{Keynote Talk TWO}

Speaker: Professor Cristian Sorin Calude, Auckland University New Zealand

Topic: Do We Need Quantum Random Generators?

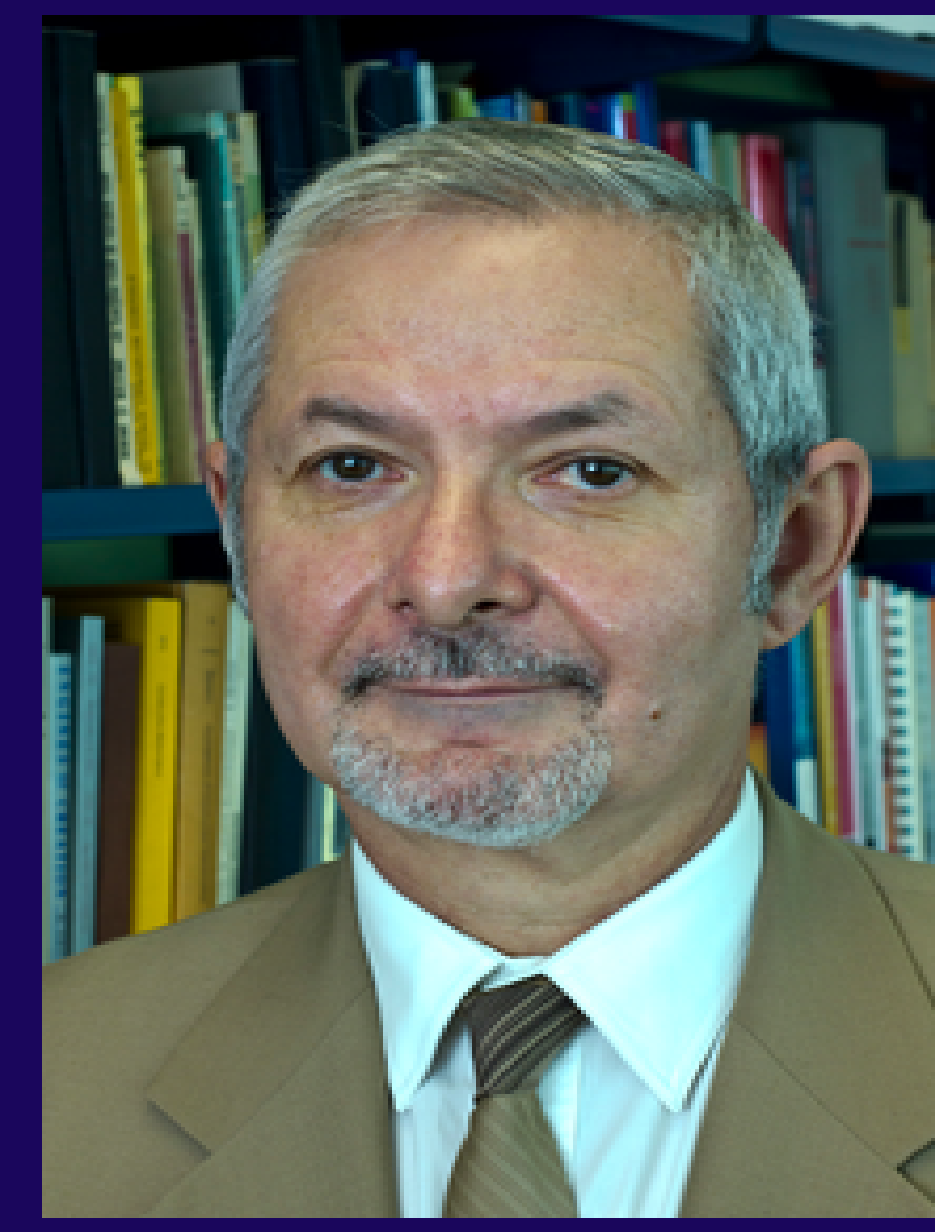

\section{BRIEF BIO}

Professor Cristian Sorin Calude is a Romanian-New Zealander mathematician and computer scientist.

After graduating from the Vasile Alecsandri National College in Galaţi, he studied at the University of Bucharest, where he was student of Grigore C. Moisil and Solomon Marcus. Calude received his Ph.D. in Mathematics from the University of Bucharest under the direction of Solomon Marcus in 1977. He is currently chair professor at the University of Auckland, New Zealand and also the founding director of the Centre for Discrete Mathematics and Theoretical Computer Science. Visiting Professor in many universities in Europe, North and South America, Australasia, South Africa, including Monbusho Visiting Professor, JAIST, 1999 and Visiting Professor ENS, Paris, 2009, École Polytechnique, Paris, 2011; Visiting Fellow, Isaac Newton Institute for Mathematical Sciences, 2012; Guest Professor, Sun Yat-sen University, Guangzhou, China, 2017-2020; Visiting Fellow ETH Zurich, 2019. Former professor at the University of Bucharest. Calude is author or co-author of more than 270 research articles and 8 books, and is cited by more than 550 authors. He is known for research in algorithmic information theory, quantum computing, discrete mathematics and history and philosophy of computation.

In 2017, together with Sanjay Jain, Bakhadyr Khoussainov, Wei Li, and Frank Stephan, he announced an algorithm for deciding parity games in quasipolynomial time. Their result was presented by Bakhadyr Khoussainov at the Symposium on Theory of Computing 2017 and won a Best Paper Award. Calude was awarded the National Order of Faithful Service in the degree of Knight by the President of Romania, Mr. Klaus Iohannis, in June 2019.

\section{ABSTRACT}

Quantum random number generators (QRNGs) have proliferated in the last decade because higher quality randomness is required in many areas, from cryptography, statistics, information science to medicine, and the many pitfalls, sometimes catastrophic, of pseudorandom number generators (PRNGs). QRNGs claim to be better than PRNGs, but are these assertions true? In this talk we will present a QRNG based on a new theory of quantum randomness which guarantees the maximal unpredictability of its quantum random digits, a quality no PRNG can match. 
Zoom 1 Link Zoom 2 Link

Zoom 3 Link
Meeting ID: 91229124156 Meeting ID: 99870482510 Meeting ID: 96481020864
Passcode: 529147

Passcode: 998668

Passcode: 739330

\begin{tabular}{|c|c|}
\hline \multicolumn{2}{|c|}{ Date: 08th December 2021; Time: 18:00 - 19:30 AEST } \\
\hline \multicolumn{2}{|l|}{ PHD THESIS SYMPOSIUM } \\
\hline \multicolumn{2}{|c|}{ Chair: Professor A B M Shawkat Ali, The University of Fiji, Fiji } \\
\hline \multicolumn{2}{|c|}{$\begin{array}{l}\text { Panel Members: Professor Girija Chetty, Professor Rajkumar S. Pant, Assoc. Professor Bibhya Sharma, Dr. Michael J. } \\
\text { Dinneen, Assoc. Professor Md. Golam Rabiul Alam }\end{array}$} \\
\hline PhD Candidate & Supervisor and Institute Details \\
\hline $\begin{array}{l}\text { Ggaliwango Marvin } \\
\text { CSDE14 \& CSDE20 }\end{array}$ & $\begin{array}{l}\text { Associate Professor Md. Golam Rabiul Alam } \\
\text { BRAC School of Data and Sciences, BRAC University, Bangladesh }\end{array}$ \\
\hline $\begin{array}{l}\text { Tim Giese } \\
\text { CSDE138 }\end{array}$ & $\begin{array}{l}\text { Prof. Dr.-Ing Reiner Anderl } \\
\text { Computer Aided Design, Technische Universität Darmstadt, Germany }\end{array}$ \\
\hline $\begin{array}{l}\text { Mojgan Hafezi Fard } \\
\text { CSDE244 }\end{array}$ & $\begin{array}{l}\text { Dr. Krassie Petrova } \\
\text { School of engineering, computer and mathematical sciences, Auckland University of } \\
\text { Technology, New Zealand }\end{array}$ \\
\hline $\begin{array}{l}\text { RAMFUL Raviduth } \\
\text { CSDE30 \& CSDE35 }\end{array}$ & $\begin{array}{l}\text { Professor Sachiko Sukigara } \\
\text { Department of Advanced Fibre Science, Kyoto Institute of Technology, Japan }\end{array}$ \\
\hline $\begin{array}{l}\text { Hanif Auwal Ibrahim } \\
\text { iCISTE26 }\end{array}$ & $\begin{array}{l}\text { Dr. Michael Ayomoh } \\
\text { Industrial and Systems Engineering, University of Pretoria, South Africa }\end{array}$ \\
\hline $\begin{array}{l}\text { Xudong Hu } \\
\text { CSDE188 }\end{array}$ & $\begin{array}{l}\text { Associate Professor Biplab Sikdar } \\
\text { Electrical and Computer Engineering, National University of Singapore, Singapore }\end{array}$ \\
\hline $\begin{array}{l}\text { iCOSTE46 } \\
\text { Amna Farrukh }\end{array}$ & $\begin{array}{l}\text { Dr. Sanjay Mathrani } \\
\text { School of Food and Advanced Technology, Massey University, Auckland, New Zealand }\end{array}$ \\
\hline
\end{tabular}

\begin{tabular}{|c|c|}
\hline \multicolumn{2}{|c|}{ Date: 08th December 2021; Time: 18:00 - 20.00 AEST } \\
\hline \multicolumn{2}{|c|}{ Special Session 1: 3D Vision, Virtual and Augment Reality } \\
\hline \multicolumn{2}{|c|}{ Chair: Associate Professor Md. Ashraful Alam, BRAC University, Bangladesh } \\
\hline Paper ID & Paper Title \\
\hline CSDE65 & $\begin{array}{l}\text { Run or Pat: Using Deep Learning to Classify the Species Type and Emotion of Pets } \\
\text { Richard O. Sinnott, Uwe Aickelin, Yunjie Jia, Elizabeth R.J. Sinnott, Pei-Yun Sun and Rio Susanto }\end{array}$ \\
\hline CSDE68 & $\begin{array}{l}\text { Canteen Automation System: An Approach for "Smart City" Planning } \\
\text { Syeda Tanzina Farhin Toma, Dolan Karmaker, Sumaiya Iqbal, Md Humayun Kabir Pantho and } \\
\text { Raihana Shams Islam Antara }\end{array}$ \\
\hline CSDE70 & $\begin{array}{l}\text { Improved Prediction of Monthly Pan Evaporation Utilising Support Vector Machine Technique } \\
\text { Mustafa Abed, Monzur Imteaz, Ali Najah Ahmed and Yuk Feng Huang }\end{array}$ \\
\hline CSDE122 & $\begin{array}{l}\text { Covid-19 Tracker: A data visualization tool for timeseries data of pandemic in India } \\
\text { Yaksh Talavia, Priyanka Singh and Sathiamoorthy Manoharan }\end{array}$ \\
\hline CSDE123 & $\begin{array}{l}\text { Deep Learning Method for Haze Prediction in Singapore } \\
\text { Azam Che Idris and Hayati Yassin }\end{array}$ \\
\hline CSDE129 & $\begin{array}{l}\text { Mobility Assistance for Visually Impaired Using LiDAR } \\
\text { Vikrant Gurav, Kevin Sherla, Abhinav Parameshwaran }\end{array}$ \\
\hline CSDE285 & $\begin{array}{l}\text { A Color Vision Approach Considering Weather Conditions Based on Autoencoder Techniques } \\
\text { Using Deep Neural Networks } \\
\text { Mohammad Mainuddin Raj, Samaul Haque Tasdid, Maliha Ahmed Nidra, Jobaer Noor, Sanjana } \\
\text { Amin Ria and Md. Ashraful Alam }\end{array}$ \\
\hline CSDE159 & $\begin{array}{l}\text { Detection of Malicious URLs through an Ensembleof Machine Learning Techniques } \\
\text { U Ananthanagu, Manav Agarwal, Rishab Kashyap, Shreya Panale, Shreya Venugopal }\end{array}$ \\
\hline
\end{tabular}


Zoom 1 Link

Zoom 2 Link

Zoom 3 Link
Meeting ID: 91229124156 Meeting ID: 99870482510

Meeting ID: 96481020864
Passcode: 529147

Passcode: 998668

Passcode: 739330

\section{IEEE CSDE \& i-COSTE 2021 - Day 2}

\subsection{2 .2021}

\begin{tabular}{|c|c|}
\hline Date: $09^{\text {th }} \mathrm{D}$ & nber 2021; Time: 09:00-10.30 AEST \\
\hline Session: 2 & \\
\hline Chair: Dr. Al & w Chiou, CQUniversity, Australia \\
\hline Paper ID & Paper Title \\
\hline CSDE3 & $\begin{array}{l}\text { An Overview of Gamification in Conflict Resolution and Complex Problems Using Scaled Down Arenas } \\
\text { in Areas of Contention } \\
\text { Maneerat Rumsamrong and Andrew Chiou }\end{array}$ \\
\hline CSDE22 & $\begin{array}{l}\text { A Performance Comparison of Fake News Detection Approaches } \\
\text { Richard O. Sinnoty and Haichao Zhu }\end{array}$ \\
\hline CSDE31 & $\begin{array}{l}\text { The impact of demographics on user satisfaction in cloud-based payment systems in Australia } \\
\text { Domingos Mondego and Ergun Gide }\end{array}$ \\
\hline CSDE8 & $\begin{array}{l}\text { Supporting End User Comprehension in Intelligent Decision Support Systems Using Data Visualisation } \\
\text { Techniques } \\
\text { Maneerat Rumsamrong and Andrew Chiou }\end{array}$ \\
\hline CSDE36 & $\begin{array}{l}\text { Deep AE: application to financial mathematics } \\
\text { Yuga Iguchi, Riu Naito, Yusuke Okano, Akihiko Takahashi and Toshihiro Yamada }\end{array}$ \\
\hline CSDE42 & $\begin{array}{l}\text { Retail Analytics to anticipate Covid-19 effects Using Big Data Technologies } \\
\text { Jesssica, Deepikesh and Krishneel }\end{array}$ \\
\hline
\end{tabular}

\begin{tabular}{|c|c|}
\hline Date: $09^{\text {th }} \mathrm{D}$ & nber 2021; Time: 09:00-10.30 AEST \\
\hline Session: 3 & \\
\hline Chair: Dr M & Jha, CQUniversity, Australia \\
\hline Paper ID & Paper Title \\
\hline CSDE77 & $\begin{array}{l}\text { Cyber-Physical Systems and Digital Twins in Practice - A Real-Life Application Example } \\
\text { Ulrich Dahmen, Marc Priggemeyer, Jürgen Roßmann }\end{array}$ \\
\hline CSDE60 & $\begin{array}{l}\text { Autonomous UAV Landing on Mobile Platforms } \\
\text { Darmesh Kumar, Jai Raj, Krishna Raghuwaiya and Jito Vanualailai }\end{array}$ \\
\hline CSDE62 & $\begin{array}{l}\text { Social Media Rumour Detection through Graph Attention Networks } \\
\text { Xinpeng Zhang, Shuzhi Gong and Richard O. Sinnott }\end{array}$ \\
\hline CSDE69 & $\begin{array}{l}\text { Finding the drivers for ERP systems uptake in SMEs - an exploratory multiple-case study of selected } \\
\text { Fijian companies } \\
\text { Sanmugam Goundar, M.G.M Khan and Karuna Garan Reddy }\end{array}$ \\
\hline CSDE75 & $\begin{array}{l}\text { Decoy-File-Based Deception without Usability Degradation } \\
\text { Yu Aoike, Masaki Kamizono, Masashi Eto, Noriko Matsumoto and Norihiko Yoshida }\end{array}$ \\
\hline CSDE38 & $\begin{array}{l}\text { A Conceptual Framework to Enhance Business Performance using Social Media: An Australian Context } \\
\text { Meena Jha, Suresh Khatiwada and Lily Li }\end{array}$ \\
\hline
\end{tabular}


Zoom 1 Link

Zoom 2 Link

Zoom 3 Link
Meeting ID: $912 \quad 29124156$

Meeting ID: 99870482510

Meeting ID: 96481020864
Passcode: 529147

Passcode: 998668

Passcode: 739330

\begin{tabular}{|c|c|}
\hline \multicolumn{2}{|c|}{ Date: 09th December 2021; Time: 09:00 - 10.30 AEST } \\
\hline \multicolumn{2}{|l|}{ Session: 4} \\
\hline \multicolumn{2}{|c|}{ Chair: Dr Md Mamunur Rashid, CQUniversity, Australia } \\
\hline Paper ID & Paper Title \\
\hline CSDE108 & $\begin{array}{l}\text { A Deep Reinforcement Learning Scheduler with Back-filling for High Performance Computing } \\
\text { Lingfei Wang, Aaron Harwood and Maria A. Rodriguez }\end{array}$ \\
\hline CSDE121 & $\begin{array}{l}\text { Churn Prediction in Telecom Industry usingMachine Learning Ensembles with Class Balancing } \\
\text { Abdullahi Chowdhury, Shahriar Kaisar, Md Mamunur Rashid, Sakib Shahriar Shafin, Joarder } \\
\text { Kamruzzaman }\end{array}$ \\
\hline CSDE132 & $\begin{array}{l}\text { Detection of Android Malware using Tree-basedEnsemble Stacking Model } \\
\text { Sakib Shahriar Shafin, Md. Maroof Ahmed, Mahmud Alam Pranto, Abdullahi Chowdhury }\end{array}$ \\
\hline CSDE137 & $\begin{array}{l}\text { Older Adults and Digital Game: Trends, Challenges and Benefits } \\
\text { Nurul Farinah Mohsin, Suriati Khartini Jali, Mohamad Imran Bandan, Nurfauza Jali, Amelia Jati Robert } \\
\text { Jupit }\end{array}$ \\
\hline CSDE141 & $\begin{array}{l}\text { Exploring the Evolutionary Characteristics of Project Management Approaches at Different Levels of } \\
\text { Operations } \\
\text { Nazish Saleem, Sanjay Mathrani and Aymen Sajjad }\end{array}$ \\
\hline CSDE147 & $\begin{array}{l}\text { Statistical Methods for Data mining Mathematics students' online presence } \\
\text { Mohammed Naseem, Emmenual Reddy and Ravneil Nand }\end{array}$ \\
\hline
\end{tabular}

\section{Tea and Coffee Break}

\section{Time: 10.30-11.00 AEST}

\begin{tabular}{|c|c|}
\hline Date: 09th & cember 2021; Time: 11:00 - 13.00 \\
\hline Session: 5 & \\
\hline Chair: Asso & Professor Norsaremah Salleh, International Islamic University Malaysia, Malaysia \\
\hline Paper ID & Paper Title \\
\hline CSDE14 & $\begin{array}{l}\text { A Machine Learning Approach for Predicting Therapeutic Adherence to Osteoporosis Treatment } \\
\text { Ggaliwango Marvin and Md Golam Rabiul Alam }\end{array}$ \\
\hline CSDE17 & $\begin{array}{l}\text { A Comparative Analysis of Hyper-parameters using Neural Networks for E-mail Spam Detection } \\
\text { Syed Mahbubuz Zaman, Md. Mohidul Hasan, Redwan Islam Sakline, Dipto Das and Md. Ashraful Alam }\end{array}$ \\
\hline CSDE20 & $\begin{array}{l}\text { Cardiotocogram Biomedical Signal Classification and Interpretation for Fetal Health Evaluation } \\
\text { Ggaliwango Marvin and Md. Golam Rabiul Alam }\end{array}$ \\
\hline CSDE28 & $\begin{array}{l}\text { A new Dataset of Wideband Radar Signals for Training Deep Neural Networks on Classification and } \\
\text { Detection Tasks } \\
\text { Mohamed A. Ammar, Mohamed S. Abdel-Latif, Khaled Mahmoud Badran, Hossameldin A. Hassan }\end{array}$ \\
\hline CSDE37 & $\begin{array}{l}\text { Multi-modal Emotion Recognition for Determining Employee Satisfaction } \\
\text { Farhan Uz Zaman, Maisha Tasnia Zaman, Saadat Hussain, Nahian Kabir, Md. Ashraful Alam, Md. Golam } \\
\text { Rabiul Alam }\end{array}$ \\
\hline CSDE46 & $\begin{array}{l}\text { Multi-dimensional comparison and selection of high-quality drinking water renovation project schemes } \\
\text { for communities } \\
\text { Zeng Jiayu, Liu Siwei, Lu Yao, Cao Haochen, Zhu Yanping and Shu Shihu }\end{array}$ \\
\hline CSDE07 & $\begin{array}{l}\text { Australian COVID-19 Data Visualization and Forecasting } \\
\text { Proma Ali, Ayesha Reddy and Mohammed Zameel }\end{array}$ \\
\hline
\end{tabular}




\title{
Older Adults and Digital Game: Trends, Challenges and Benefits
}

\author{
Nurul Farinah Mohsin, Suriati Khartini Jali, Mohamad Imran Bandan, Nurfauza Jali, Amelia Jati Robert Jupit \\ Faculty of Computer Science and Information Technology \\ Universiti Malaysia Sarawak \\ Sarawak, Malaysia \\ 19020202@siswa.unimas.my, jskhartini@unimas.my,bmimran@unimas.my,jnurfauza@unimas.my, rjajati@unimas.my
}

\begin{abstract}
The usage of digital games is not limited to entertainment purposes. It can be used in healthcare and social science studies focusing on older adults as the main subject. The objectives of this review are to identify the challenges related to older adults, the benefits they gained using the digital game, and the method used in previous studies. There are 27 articles reviewed based on keywords searched in Scopus database. These studies are evaluated regarding their approaches, challenges and benefits of digital games highlighted in their studies. Finally, several improvable points in the current approaches are highlighted and suggestions are provided as further works.
\end{abstract}

Keywords - andragogical perspectives, benefits, challenges, digital game, older adults

\section{INTRODUCTION}

Digital gaming is widely known as an entertainment tool. However, the currently available games in the market are designed and developed specifically for the younger users in mind. The potential of digital games can be seen in healthcare, primarily focusing on older adults specifically. According to [1], digital games can be used as technology to enhance older adult's life by providing enjoyment. Serious game is a game that serves the purpose of improving the daily activities of older adults such as vision, balance and memory [2]. It can help older adults improve physical and cognitive functions [3].

To attract the attention of older adults and utilise their cognitive abilities, it is crucial to apply the key principles of andragogy while designing and developing the game. Andragogy is an art and science of helping adults to learn. According to the principles of andragogy, older adults who understand the rationale of playing, know the game, and acknowledge the importance of the digital game will make the process of the gameplay session run smoothly and increase their motivation and attention.

The principal focus is a systematic review of gaming studies, platform and technology for seniors gleaned from the Scopus database. This review paper aim is to conduct a systematic review on the game platform and technology used in previous studies between 2015 to 2020 , the challenges for older adults to interact, and experience the digital games and the benefits they gain from interacting with digital games computer game is commonly referred to as an entertainment instrument. However, the games currently on the market are specifically designed and developed for the younger user in mind.

\section{METHODOLOGY}

\section{A. Data Collection}

There are two methods used for data collection, keywords identification and database, period researched and review process.

\section{1) Keywords Identification}

The first step in this systematic literature review is to define keywords used to ensure the process of this research runs smoothly and meets the purpose of this re-view. The keywords used in this review is ("older adults AND digital game") OR ("andragogy").

\section{2) Database, Period Researched and Review Process}

Scopus, the chief database source was used to identify relevant articles containing the identified keywords. Only publications published from 2015 until 2020 were selected for this review. Publication from 2015-2020 were selected to understand the gap knowledge related to older adults and digital gaming in recent years. The articles selection for review are based on abstract, target groups, and language used in the published articles. Only articles written in English and the target group focussing on older adults are selected for this review paper.

\section{B. Data Analysis}

There are four data are analysed in this paper, game platform and technology, challenges related to older adults, benefits gains through playing digital games and research purposes and methodologies used in previous studies.

\section{1) Game Platform and Technology}

The previous researchers used many types of game technology and game platform in their studies. In this review, it only focuses on mobile, console, and web-based game technology.

\section{2) Challenges Related to Older Adults}

There are many challenges related to older adults interacting with digital games and we group it based on four categories: 